\title{
Blended Teaching Research of Advanced Stratification, Learning Classification and Goal Classification
}

\author{
Jing Liang 1,a, ShaoJin Dong 1,b*, YaNi Zhang ${ }^{1, c}$, LiNa Yan ${ }^{1, d}$ \\ 1 College of Information and Communication National University of Defense Technology, Xi'an, Shaan'xi, China \\ a1628328@qq.com \\ b*361015138@qq.com \\ cwaterlilyyani@163.com \\ d13760016@qq.com
}

\begin{abstract}
Aiming at the problems of unclear teaching content characteristics, teaching organization form and content to be optimized, students ' information literacy needs to be strengthened, and multi-party linkage talent training mechanism is not perfect in the training of preselected non-commissioned officers(NCO) for data exchange equipment operation specialty, this paper takes online and offline blended teaching as the main starting point and uses online and offline blended teaching to promote the teaching reform of data exchange equipment operation specialty, enrich the form of equipment operation and maintenance practice teaching activities, expand the training channels of equipment operation and maintenance talents, and promote the improvement of students ' innovative and practical ability. Formed an "advanced stratification, learning classification and target classification" of data exchange equipment operation professional personnel training qulity improvement model, which well supports the construction of data exchange equipment operation specialized subject.
\end{abstract}

Keywords: Micro Lecture, MOOC, Blended Teaching, Instructional design, Preselected NCO

\section{“进阶分层、学习分类、目标分级” 的混合式教学研究 梁璟 $1, \mathrm{a}$ 董绍进 $1, \mathrm{~b}^{*}$ 张亚妮 ${ }^{1, \mathrm{c}}$ 严丽娜 $1, \mathrm{~d}$}

1 国防科技大学信息通信学院, 陕西 西安

a1628328@qq.com

b*361015138@qq.com

${ }^{c}$ waterlily_yani@163.com

d13760016@qq.com

\section{摘要}

针对数据交换设备操作专业预选士官人才培养面临的课程教学内容特色不鲜明、教学组织形式及内容有待优化、 学员信息素养有待加强、多方联动人才培养机制不完善等问题, 以线上线下混合式教学为主要抓手, 通过混合 来推动数据交换设备操作专业课程教学改革、丰富设备操作与维护实践教学活动形式、拓展设备操作与维护人 才培养渠道、促进学员创新实践能力提升, 形成了一种 “进阶分层、学习分类、目标分级” 的数据交换设备操 作专业人才培养质量提升模式, 很好地支撑了数据交换设备操作专业建设。

\section{关键词: 微课 慕课 混合式教学 教学设计 预选士官}

\section{1. 引言}

信息技术的高速发展对教育的支配性功能日益 以网络为基点组织起来, 网络使教学活动产生了时空
分离, 教员不再仅仅是直接的教育者, 教育目标亦可 通过在线课程甚至是仿真机器人来实现 ${ }^{[1]}$ 。

军队院校面临 “军队院校教育” “部队训练实践” 
“军事职业教育” “三位一体” 新型军事人才培养体 系建设的时代课题，同时担负强军兴军和备战打仗的 使命任务。为了助力军队院校教育高质量发展和内涵 式发展, 要充分利用网络信息技术给教育教学带来的 革命性变化, 推动以学员为中心的教学理念落实落地, 实现军队院校课堂教学和人才培养质量质的飞跃 ${ }^{[2]}$ 。

\section{2. 混合式教学的必要性}

无论是在校还是在线教育, 目标都是全面提高官 兵履职能力和职业素养。具体来说, 就是要求我们组 织各类教学活动时, 在传统课堂教学的基础上, 还要 紧密结合军队建设发展和官兵成长成才需要, 普及开 展有组织有计划的自主学习, 逐步实现全员、全时、 全域的在岗继续教育, 使军队人员得到与军事变革、 岗位要求和职业发展相适应的教育培训, 知识结构及 时更新, 履职能力和职业素养全面提高, 为实现强军 目标、建设世界一流军队提供有力人才保障。简单地 说, 就是通过打造普适性的信息化环境条件, 有效解 决广大官兵日益增长的学习需求与学习资源不充分 之间的矛盾。

军校的混合式教学是以军事职业教育建设发展 为牵引, 着眼当前军队院校课堂教学改革和军事职业 教育课程建设的现实需求, 在总结前期数字媒体资源 建设经验的基础之上, 认真研究任职教育特点规律, 多方开展调研学习, 采取边建设边探索边完善的思路 方法进行建设。

\section{3. 国内外主要研究现状}

课堂是传统高等教育的主阵地，而这种限定时间、 统一教材、资源、方法、考核的标准化、流水线、单 向传输的培养模式存在固有的教学问题。

自 2001 年以来以麻省理工学院开放式课程 (Open Course Ware, OCW) 计划为代表开放教育资源 运动, 以及 2012 年以来慕课 (Massive Open Online Course, MOOC) 出现和大规模广泛应用, 其所共享的 优质教育资源, 使得系统学习、全时学习和个性学习 得以蓬勃发展。而单纯的 $0 \mathrm{CW}$ 或慕课均存在一定缺点, 如师生交流缺乏时效、教学氛围不足、缺乏教学方式 多样性、质量难以保证等。在具体实施过程中, 以小 规模限制性在线课程 (Small Private Online Course, SPOC) 为代表的 “混合式教学” 模式, 融合了实体课 堂与在线教育二者的优势, 已成为当前高校课堂教学 改革与创新的重要实践方式。

2015 年 3 月, 教育部印发的《2015 年教育信息 化工作要点》中指出要坚持促进信息技术与教育教学 深度融合的核心理念。自此混合式教学模式逐渐被高 校认可。

2019 年 4 月, 教育部启动一流本科专业建设 “双 万计划”, 即在 2019 年至 2021 年建设一万个左右国 家级一流本科专业点和一万个左右省级一流本科专
业点。这标志着基于慕课应用等信息技术与传统教育 教学深度融合这一 “课堂革命”的全面推广。

\section{1. 国外混合式教学发展现状}

2000 年是混合式教学元年, 最早由 Cooney 等人 ${ }^{[3]}$ 在学龄前儿童教育研究中首次提出, 在此后十几年 里, 国外有关它的理论和实证研究得到了迅速发展。 在实际教学操作中, 混合式教学也在被快速推广, 从 2000 年到 2004 年短短几年内, 美国已经有接近一半 的高校向本科生提供混合式学习课程, 美国《校园科 技》杂志在 2016 年首次开展 “技术辅助教学” 调查 发现, $71 \%$ 的美国高校教员在教学中使用在线和面对 面混合式教学环境。美国新媒体 2019 年《地平线报 告》高等教育版指出混合式学习融合了在线学习方式 和面对面学习方式的最佳实践经验, 并连续第四次把 它列为未来 1-2 年内高等教育发展趋势之一。

\section{2. 国内混合式教学发展现状}

混合式学习在国内的研究虽然开始较晚, 但近年 来, 混合式学习理论也受到了国内高等教育领域的充 分重视, 从 2009 年以来, 相关研究呈明显增长趋势 ${ }^{[4]}$ 。

国内高等教育界一直主张以研促教, 希望用学术 及教学研究促进高校教员更新教学理念、开展创新教 学、改革教学方法。祝智庭和孟琦首次将混合式学习 介绍到国内, 随后三年里, 有关混合式学习的研究不 多, 基本处于理论研究阶段, 实际应用较少。从 2009 年以来, 相关研究呈明显增长趋势, 尤其是近 10 年 里, 有关混合式学习的发文量快速增长, 涵盖了基于 技术平台的混合式学习系统建设与应用研究, 基于网 络公开资源的混合式学习设计和实践 ${ }^{[5]}$, 通过实证研 究探讨混合式学习模式的有效性, 以及混合式学习设 计在具体某个课程中的应用等。混合式学习的理论和 实践研究, 结合国内信息化技术和各种软硬件产品更 新发展, 使各种形式的混合式学习在国内各大院校的 开展成为可能。

南京工业大学的郑静 ${ }^{[6]}$ 调查了来自江苏省 16 所 高校、教龄在 11-20 年、涉及 16 个专业的教员, 数 据显示有近 70\%的国内高校教员在开展不同程度的混 合式教学, 这一数据已经接近美国 2016 年的统计数 据, 说明虽然混合式学习研究在国内开展相对较晚, 但随着我国信息化软硬件技术的迅速发展和更新, 以 及国内高校教学改革不断推陈出新, 教员接受和运用 教学新技术和新理念的能力也在迅速迭代跟进。

地方高校正大力建设和发展 “MOOC-Inside” 和 “MOOC+SPOC+翻转课堂” 等混合教学模式, 课程教学 整体水平和人才培养质量不断提升。目前混合教学模 式的研究和应用, 主要聚焦于大专、本科和研究生教 育, 在学员的学习能力和积极性均较好情况下, 混合 教学模式体现出了较大的优势。但是针对军校学员尤 
其是预选士官学员的相关研究, 目前并无具体实践。

\section{4. 混合式教学探索与实践}

通过对数据交换设备操作专业预选士官学员的 《路由交换设备配置》课程进行教学研究探索，在充 分研究和掌握预选士官学员特点的基础上, 按照课程 特点分析、教学模式设计、设定学习效果、知识梳理
归纳、基于问题的学习、多维评价机制、教学反馈反 思的总过程, 进行了混合式教学的分析、探索和实践 尝试。通过设置课程前、课程中、课程后三环节，结 合教学目标、方式方法、学员学习三个维度, 总体设 计如图 1 所示。

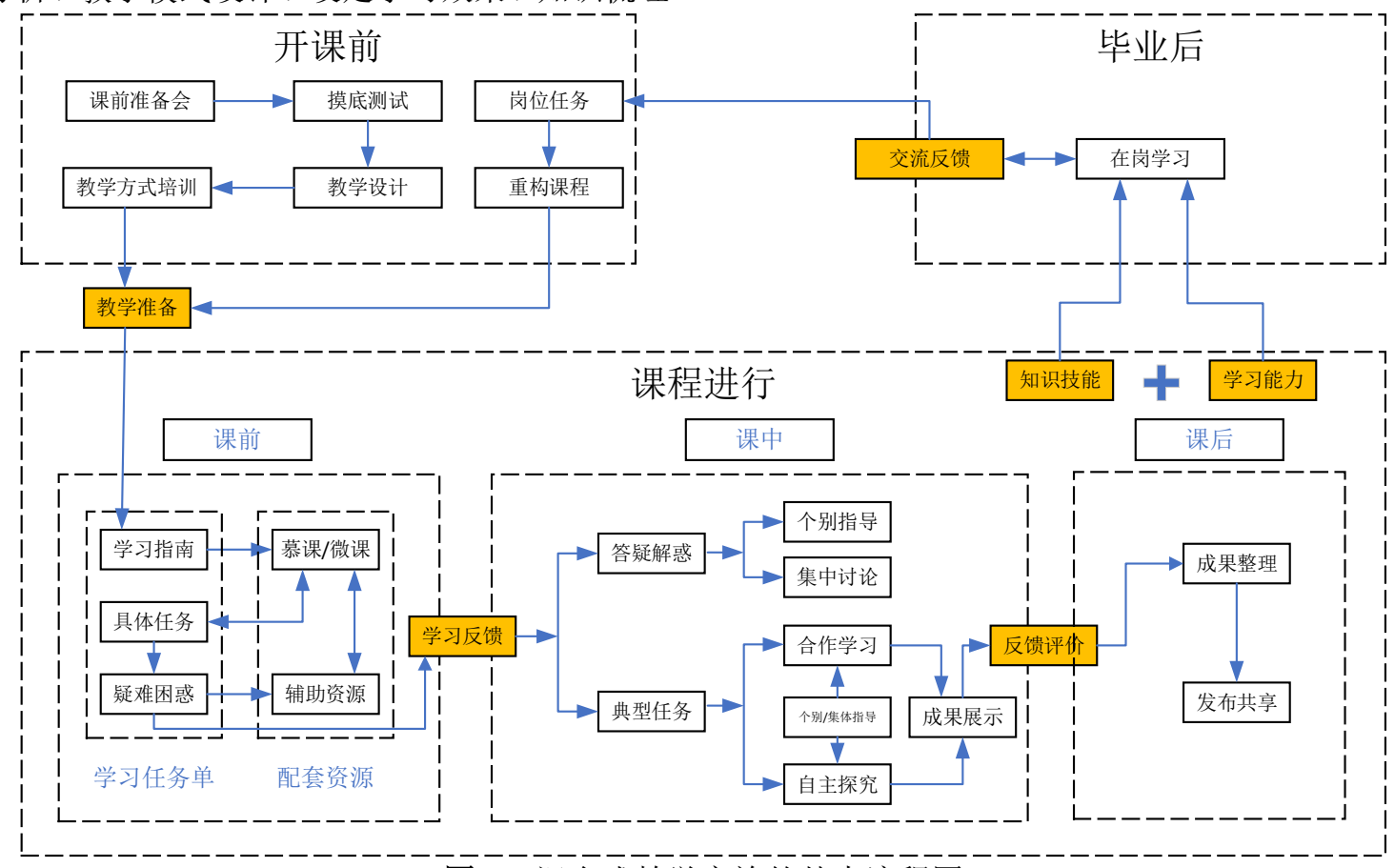

图 1 混合式教学实施的基本流程图

通过梳理分析, 将混合式教学的混合分为四个层 次, 将课程内容体系进行了重构, 把知识点分为三大 类, 在制定个人成长路线图的同时将目标分级, 形成 了 “进阶分层、学习分类、目标分级” 的全程化专业 能力培养新模式。

\section{1. 进阶分层}

通过大量阅读相关文献及梳理, 将混合式教学分 为四个层次, 即进阶分为四层。

\subsection{1 第一个层次一线上与线下的混合}

即将在线教学资源引入传统教室学习。通常理论 类课程适合这个层次的教学模式。主要原因在于, 学 员入校时普遍基础不足、学习能力和学习积极性不高, 需要强有力的监督机制, 才能逐步提升专业基本素质 和自学能力。对于理论类的计算机网络、信息安全技 术两门课程, 慕课平台有大量国家级精品课程可供参 考, 课程的建设和维护质量都很高, 可充分利用这些 资源作为课前预习、课后复习和自主深入学习的材料。

\subsection{2 第二个层次一基于学习目标的混合}

即在 “混合” 策略的设计上以 “达成学习目标”
为最终目标, 混合的学习内容和方式更为广泛。基于 目标的混合式学习既可能都是传统方式的, 例如: 课 堂培训与读书以及讨论会相结合的混合学习, 又可能 都是在线方式的混合，例如：通过网络虚拟教室学习 与 BBS 讨论相结合的在线学习等等。因此, 该层次的 混合式学习又被称为 “整合式学习”。理论类课程的 少部分知识和操作类课程主要处于这个层次, 其主要 原因是此时学员已经通过理论类课程掌握相应的专 业基础知识和基本的自学方法, 也通过前置课程的小 组讨论和小组实验等形式建立了较为稳定的相互协 作交流关系。

\subsection{3 第三个层次一“学”与 “习” 的混合}

“学” 与 “习” 的混合才是混合式学习的真正内 涵。通过 “习” 将学习的内容应用到实践中去, 这是 学习更高层次的目的。通常情况下, 我们将 “学” 等 同于学习，而实际情况将 “习” 完全遗漏掉了，绝大 多数的面授或在线学习都只是 “学” 而已, 并不是真 正意义的学习。实际上, 设计 “学” 与 “习” 的混合 才是最有效的混合式学习。而这种混合式学习在设计 上其实又是最核心的。操作类课程的部分内容和综合 训练类课程都处于这个层次。这个层次的难点在于, 知识的 “习”所用的时间可能远远多过 “学” 的时间, 
才能达成课程学习目标。这就要求教员要综合使用多 种方法手段, 调动学员利用课余时间进行 “习” 的积 极性和主动性。

\section{1.4 第四个层次一学习与工作的混合。}

学习与工作相结合的混合式学习又被称为 “嵌入 式” 的学习或 “行动学习”, 与其说是一种学习方法, 不如说是一种学习境界。从某种意义上来说, 工作本 身就是学习。通常综合训练类课程的部分内容处于这 个层次。当学员走上工作岗位以后就一直处于这个层 次, 这又要求我们为处于工作状态的学员提供 “学” 的途经, 也就是目前正在大力发展的军事职业教育。

\section{2. 学习分类}

学习, 是指通过阅读、听讲、思考、研究、实践 等途径获得知识和技能的过程。在我们平时的教学过 程中, 通常将学习笼统的作为一个整体去看待。而在 实际教学过程中, 学和习是各自独立又密不可分的两
个部分, 通过将学习过程的学与习进行区分, 可以更 好的了解教学组织中学及习的目标达成情况, 也可以 更有针对性的组织教学。

整个学习过程可以被规划为三个阶段。首先通过 将线上教学资源引入传统教学, 并进行课程资源的归 类和课程内容重构, 明确需要 “学” 的教学内容, 规 划“习”的训练部分, 使其符合预选士官的岗位能力; 然后对 “学” 与 “习” 这两部分内容又分别按照知识 和能力的进阶规律进行细分; 接着根据细分后的教学 内容和学员学习能力差异采用多层混合式教学方法, 以 “达成学习目标” 为目的, 调动学员 “习” 的积极 性和主动性, 通过 “习” 将学习的内容应用到实践中 去; 当然还要为学员提供持续 “学” 及 “习” 的途经 和方法, 从而提高学员的履职能力和职业素养。

为了更方便直观的区分学与习的不同类型，下面 以广域网接入技术为例通过表 1 进行说明。

表 1 “学”与 “习” 分类举例

\begin{tabular}{|c|c|c|c|}
\hline 内容 & 学习分类 & 进阶划分 & 教学组织 \\
\hline $\begin{array}{c}\text { PPP、静态路由、TELNET 综合 } \\
\text { 训练 }\end{array}$ & \multirow{2}{*}{ 习 } & 高级运用 & 小综合训练及测试 (线上训练、线下训练及测试) \\
\hline PPP 配置单点达标 & & 基础掌握 & 技能训练 (线上训练、小组帮扶及线下训练达标) \\
\hline PPP 配置流程及命令 & \multirow{3}{*}{ 学 } & 技能理论 & $\begin{array}{l}\text { 理论讲授、示范讲解、学员跟练 (线上观看慕课, } \\
\text { 答疑既线下讲解示范) }\end{array}$ \\
\hline PPP 协议理论 & & 专项理论 & 理论讲授（线上观看慕课，答疑既线下讲解） \\
\hline 广域网接入技术 & & 基础理论 & 理论讲授（线上观看慕课, 答疑既线下讲解） \\
\hline
\end{tabular}

\section{3. 目标分级}

\section{3. 1, 目标分级思路}

根据该层次和专业的培训方案, 学员在完成培训 后的知识、能力和素质方面的要求主要包括以下方面: (1) 知识上, 了解数据交换设备操作专业理论知识, 熟悉数据交换设备技术性能和值勤管理规定;（2）能
力上, 掌握必需的计算机基础知识, 具备初步的计算 机操作能力; 掌握路由器交换机的配置命令和重要业 务的配置方法, 具备一定的数据交换设备配置能力; 掌握网络服务器配置方法, 具备一定的网络服务管理 能力; (3) 素质上, 具备持续学习意识和初步的创新 精神, 能够胜任数据交换设备值机员岗位。学员的知 识能力素质成长路线如图 2 所示。 


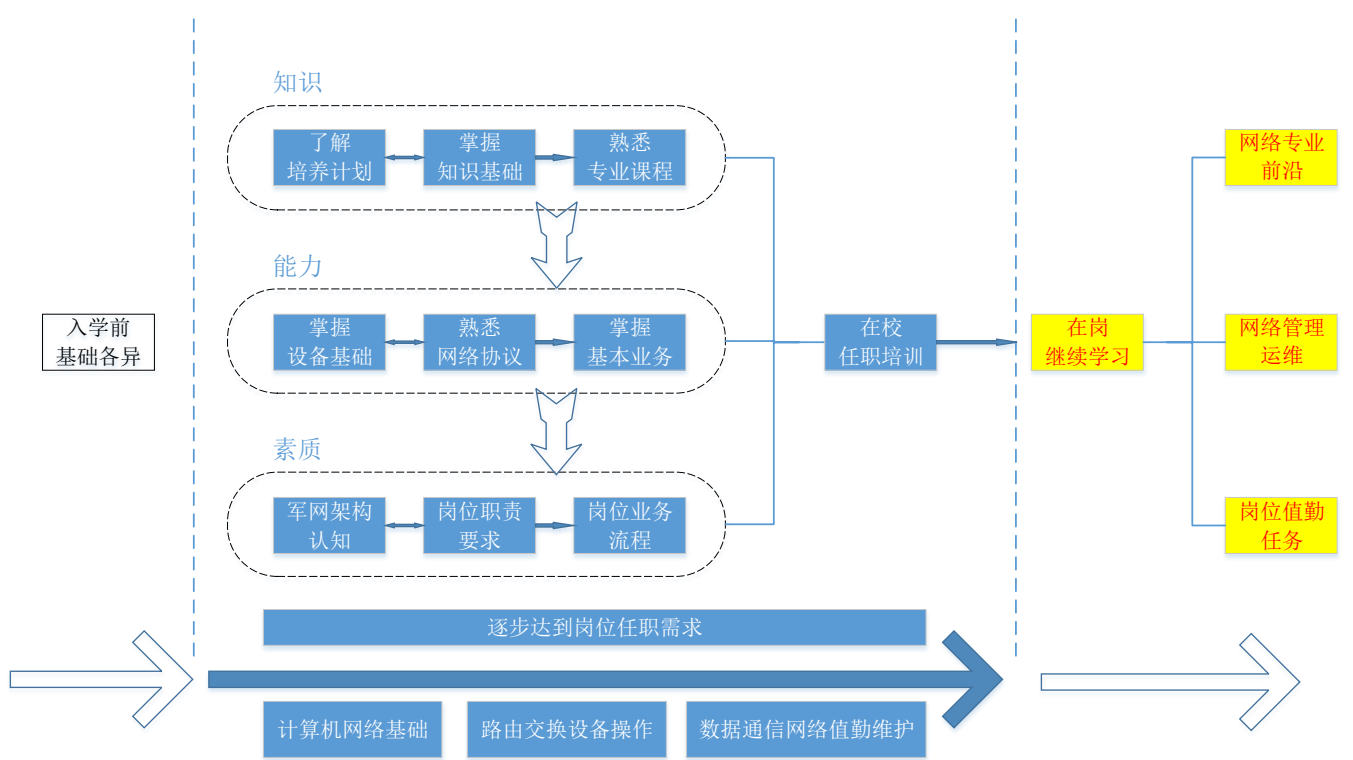

图 2 知识能力素质成长路线图

从图中可以看出, 学员在入学前知识能力基础各 异，但毕业时考核标准是统一的，考试成绩不能准确 反映学员在校学习的成长进步。因此我们制定了目标 分级的差异化考核评价方案。

\section{3.2 学员分类}

根据入学前的学历、专业和《调查表》, 综合了 解学员的知识基础和学习能力, 结合前置课程《计算 机网络基础》课程的学习情况, 瞄准课程教学目标, 按专业和学历为每名学员画像, 将学员分成四类, 如 表 2 所示。

表 2 学员分类画像表

\begin{tabular}{|c|c|c|}
\hline 学员分类 & 专业 & 学历 \\
\hline A 类学员 & 对口 & 高 \\
\hline B 类学员 & 不对口 & 高 \\
\hline C 类学员 & 对口 & 低 \\
\hline D 类学员 & 不对口 & 低 \\
\hline
\end{tabular}

此处的专业是指在部队的工作岗位与本校培训 专业之间的关系; 学历则是通过课前调查, 将本科及 本专业专科这两种划分为高学历, 其余非本专业专科
生及高中生划分为低学历。

\section{3. 3, 差异化评价标准}

本课程之前的考试分为两部分, 平时上课时的表 现及练习占 $40 \%$, 课后的集中统一考核占 $60 \%$, 这种 做法的好处是便于管理, 不足之处是与课程学习结合 不紧密, 与个人成长不结合, 不能表现出能力培养的 导向。

根据学员不同的起点将不同基础的学员对应知 识点目标分级。在不改变课程教学计划考核要求的同 时，充分考虑重难点问题和抽象概念的可视化呈现、 小组分工合作的探究式学习、学员在课堂上的多种技 术手段运用、教辅和自学考查长远发展等多方面的问 题, 根据学员能力和初始基础分别设定学习效果目标, 将占比 40\%的平时成绩进行差异化区分, 使得不同教 育起点的学员等够被区分对待。

通过改变原有考核模式，采用 “全程监控、综合 评定” 的评价方式。在内容上, 注重考理解、考应用、 考技能; 在方法上, 将笔试、口试、操作等形式相结 合; 在组织上, 针对不同的教育起点的学员, 制定差 异化考核标准, 综合运用多种考核方式, 全面的、有 区分的考核学员的专业能力。整个考核过程如图 3 所 示。 


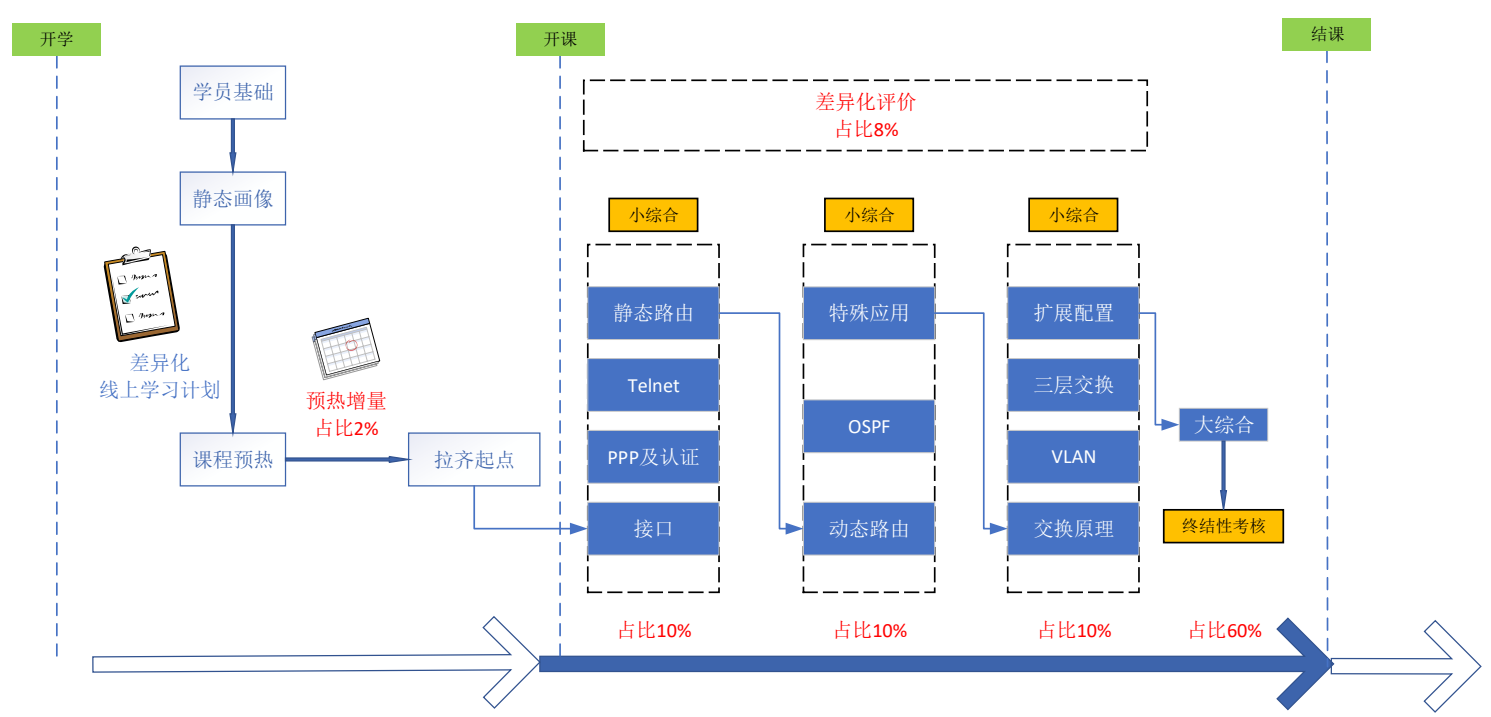

图 3 考核方式及过程

考核评价过程中的统一化标准有: 上课单点达标、 小综合、终结性考核, 总共占 $90 \%$ 。对于 10\%的差异 化考核, 分别体现在两个方面。

在预热阶段, 通过精准画像, 得到每个学员的学 习起点, 制定差异化线上学习计划, 通过视频观看次 数, 视频观看时长, 发回帖次数, 在线学习测试等统 计信息, 形成课前预热增量, 占比 $2 \%$, 反映对本课 的学习态度及学习能力。

在实践过程中, 设置了 $8 \%$ 的差异化部分, 按学 员的四种类型，分别制定了四个标准：

$A$ 类学员: 主要关注组训施教能力, 具体为小教 员授课效果评价 $* 0.7++$ 线上资源清单完成度 $* 0.3$;

$B$ 类学员: 主要关注整体的传帮带能力, 具体为 组内帮学效果评价 $* 0.6++$ 线上资源清单完成度 $* 0.4$;

$C$ 类学员：主要关注小组和团队意识, 具体为学 习结对子效果评价 $* 0.5++$ 线上资源清单完成度 $* 0.5$;

D 类学员: 主要关注学习任务完成情况, 具体为 线上测试 $* 0.3+$ 笔记整理 $* 0.1+$ 线上资源清单完成度 *0. 6 。

\section{5. 混合式教学实践提升人才培养质量}

\section{1. 提高了课堂教学质量}

本课题在试验训练基地 2019 春季、2020 年秋(夏) 季学期预选士官培训班次数据交换设备操作专业 9 队 6 区队《路由交换设备配置》课程及网络安防专业 14 队 3 区队《网络设备配置》课程中进行了教学实 践, 按照线上线下混合式教学安排, 学员通过自习时
间自学指定的线上学习内容, 在课堂授课时能够带着 问题学习、较快抓住知识重点、学习针对性更强、学 习效果反馈有渠道。通过线上线下混合式教学, 学员 的学习兴趣明显提升、锻炼了自主学习和发现问题的 能力, 线上学习资源中的动画视频使得理论知识不再 枯燥, 实践内容可以课后反复跟练, 及时解决课堂遗 留问题, 激发了学员的学习兴趣, 拓展了学员的视野, 显著提升了课堂教学质量, 取得了较好的教学效果。

\subsection{1 纵向对比}

本混合式教学方法在 2019 春季、2020 年秋(夏) 季学期预选士官培训班次数据交换设备操作专业 9 队 6 区队《路由交换设备配置》课程中进行了教学实 践。

对于 2019 期学员提供了线上学习资源, 学员根 据自己的课余时间进行线上自学;

对于 2020 期学员，由于经过一年多的时间对线 上资源进行了不断完善，对线上线下混合式教学模式 进行了不断优化, 为 2020 期学员提供了线上学习的 专用多媒体教室, 安排学员统一利用自习时间在多媒 体教室完成共 40 学时的线上学习和教员辅导。

将未进行本课题教学实践的 2018 期学员作为纵 向比较对照组，通过对 2018-2020 共三期预选士官培 训班次《路由交换设备配置》课程考试成绩进行对比, 如表 3 及图 4 所示。可以看出, 经过本课题教学实践, 2019 期相较 2018 期学员的课程考试成绩获得了较为 明显的提高; 2020 期相较 2019 期及 2018 期学员的 课程考试成绩获得了显著提高, 课程考试优良率超过 $50 \%$ ，通过率达到 100\%。 
表 3 三期预选士官班次课程考试成绩对比

\begin{tabular}{|c|c|c|c|c|c|c|}
\hline 年度 成绩 & 最高分 & 最低分 & 平均分 & 优良率 & 及格率 & 不及格率 \\
\hline 2018 & 93 & 15 & 66.2 & $21 \%$ & $84.2 \%$ & $15.8 \%$ \\
\hline 2019 & 94 & 48 & 72.6 & $40 \%$ & $90 \%$ & $10 \%$ \\
\hline 2020 & 98 & 61 & 81.9 & $53.3 \%$ & $100 \%$ & $0 \%$ \\
\hline
\end{tabular}
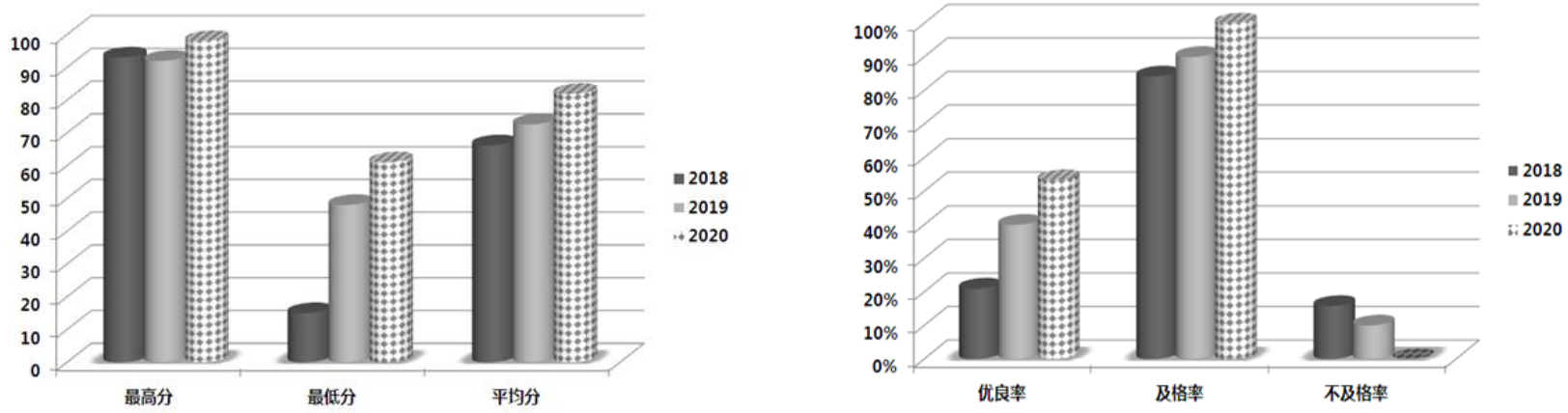

图 4 三期预选士官培训班次课程考试成绩对比

\subsection{2 横向对比}

通过对试验训练基地 2020 年秋 (夏) 季学期预 选士官培训班次 9 队 6 区队数据交换设备操作专业学 员《路由交换设备配置》课程线上学习时间差异与成 绩之间的关系进行对比。

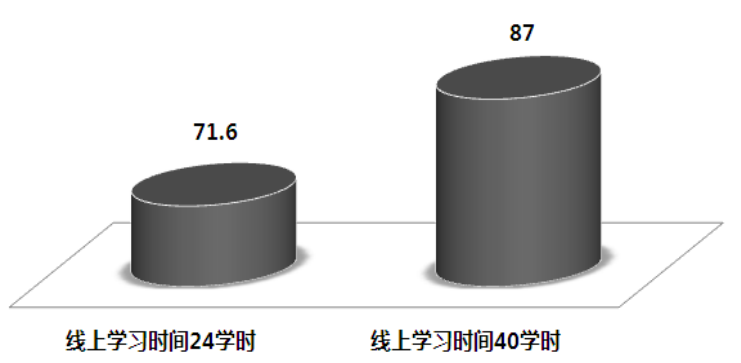

图 5 线上学习时间与课程考试成绩平均分对比

其中山四军、黄砧、罗琳盛、邓炜龙、孙俊祎等 五名学员参加心理咨询师培训与本课程线上学习部 分时间冲突, 线上学习时间为 24 学时, 相较于其他 学员少学习了 16 学时, 从图 5 可以看出线上学习时 间的长短对学习效果的影响。

\section{2. 培养了学员的自学实践能力}

(1) 在线上线下混合式教学实践过程中, 学员 在线上学习过程中遇到不清楚的问题, 可以通过线下 小组交流、线上讨论区交流、线下课堂交流等方式解 决问题。通过课程论坛和小组交流与其他同学、教员 的互动, 学员在观察、参与、学习和体验中, 培养了 自主、探究、创新和合作学习的能力。学员在线上课 程学习讨论区保持了较高的活跃度, 讨论积极热烈。
(2) 利用网络平台, 拓宽了学员的学习渠道、 学习时间和空间, 学员能充分利用自己的业余时间, 按照自己的学习节奏, 学习网络平台上的课程内容, 或是重复学习, 或是拓展学习, 更好地突出个性化学 习, 很多学员争当小教员, 为其他学员答疑解惑, 提 高了学员的学习自信和学习成就感。

(3) 在自学过程中逐渐培养了自主学习、发现 问题、解决问题和自我管理的能力, 提高了自学实践 能力和学员的信息素养, 使学员掌握使用信息技术工 具进行自学的方法, 为学员回到部队后的继续学习以 及形成一定的技术革新和解决技术难题的能力打下 良好基础, 成为学员回部队后获得更好发展的先决因 素。通过对 2020 年秋 (夏) 季学期预选士官班次数 据交换设备操作专业 9 队 6 区队（共 15 人）《路由交 换设备配置》及网络安防专业 14 队 3 区队 (共 29 人) 《网络设备配置》课程学员发放调查问卷, 结果显示, 两个教学班的学员（9 队 6 区队 3 人、 14 队 3 区队 8 人) 此前仅有少数学员能够熟练登陆国防科技军事职 业教育平台、中国 MOOC 大学等在线教育平台, 能够 通过搜索找到自己想要学习的课程进行学习; 而大多 数学员 $(9$ 队 6 区队 12 人、 14 队 3 区队 21 人) 没有 登录过或会登陆但没有搜索学习过课程, 信息素养较 差。通过本课题的线上线下混合式教学实践后, 两个 教学班的学员均已熟练掌握相关在线平台登陆、搜索 和学习课程的方法。

\section{6. 结语}

本文针对数据交换设备操作专业预选士官人才 培养面临的课程教学内容特色不鲜明、教学组织形式 及内容有待优化、学员信息素养有待加强、多方联动 人才培养机制不完善等问题, 以线上线下混合式教学 
为主要抓手, 通过混合来推动数据交换设备操作专业 课程教学改革、丰富设备操作与维护实践教学活动形 式、拓展设备操作与维护人才培养渠道、促进学员创 新实践能力提升, 形成了一种“进阶分层、学习分类、 目标分级” 的数据交换设备操作专业人才培养质量提 升模式, 显著提升了课堂教学质量, 取得了较好的教 学效果, 有效支撑了数据交换设备操作专业建设。

\section{项目基金}

本文为国防科技大学信息通信学院 2019 年度教学研究重点课题——基于慕课的 “路 由交换设备配置” 课程混合式教学探索与研 究的阶段性成果之一。(课题编号: JY19A002)

本文为国防科技大学信息通信学院金课 建设阶段性成果之一。

\section{REFERENCES}

[1] Yang Weidong, Dong Xiaoyu. Dilemma and optimization path of network curriculum construction in Colleges and universities [J]. China higher education, 2019 (10): 48-50.

[2] Comprehensively strengthen practical military training and comprehensively improve training level and winning ability [n]. PLA Daily, 2020-11-26 (01).

[3] Cooney M. H, Gupton P, O' Laughlin M. Blurring the lines of play and work to create blended classroom learning experiences[J]. Early Childhood Education Journal, 2000(3) : 165-171.

[4] Du Shichun, Fu Zetian. Blended learning based on MOOC and its empirical research [J]. China audio visual education, 2016 (12): 129-133, 145

[5] Yang Yuqin, Ni Juan. Deep learning: Teaching Reform towards core literacy [J]. Contemporary educational science, 2017 (8): 43-47

[6] Zheng Jing. Investigation and Analysis on the current situation of blended teaching in domestic colleges and universities [J]. Heilongjiang Higher Education Research, 2018 (12): 44-47 